\title{
Transitions, and the Pursuit of Happiness
}

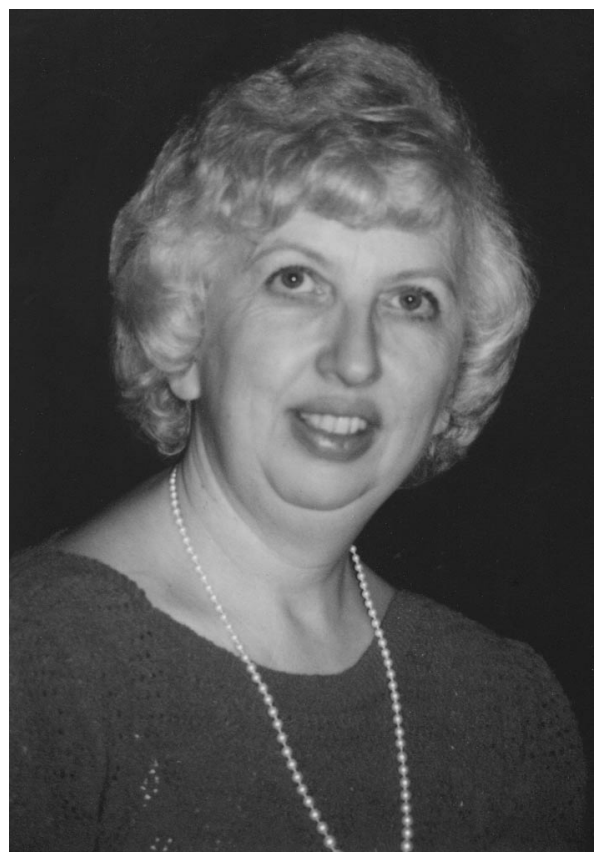

\begin{abstract}
This perspective on "happiness as a way" rather than focusing on finding a path to happiness may be particularly relevant for new and expectant parents.

Journal of Perinatal Education, 8(1), vi; expectant parents, happiness, perinatal education.
\end{abstract}

The following wisdom is one of the WorldWide Web items that get forwarded around, and I am forwarding it on to you. It goes as follows:

"We convince ourselves that life will be better after we get married, have a baby, then another. Then we are frustrated that the kids aren't old enough and we'll be more content when they are. After that we're frustrated that we have teenagers to deal with. We will certainly be happy when they are out of that stage. We tell ourselves that our life will be complete when our spouse gets his or her act together, when we get a nicer car, are able to go on a nice vacation, when we retire.

"The truth is, there's no better time to be happy than right now. If not now, when? Your life will always be filled with challenges. It's best to admit this to yourself and decide to be happy anyway.

"For a long time it had seemed to me that life was about to begin-real life. But there was always some obstacle in the way, something to be gotten through first, some unfinished business, time still to be served, a debt to be paid. Then life would begin.

"At last it dawned on me that these obstacles were my life. This perspective has helped me to see that there is no way to happiness. Happiness is the way. So, treasure every moment that you have. And treasure it more because you shared it with someone special, special enough to spend your time . . . and remember that time waits for no one . . .

"So stop waiting until you finish school, until you go back to school, until you lose ten pounds, until you gain ten pounds, until you have kids, until your kids leave the house, until you start work, until you retire, until you get married, until you get divorced, until Friday night, until Sunday morning, until you get a new car or home, until your car or home is paid off, until spring, until summer, until fall, until winter, until you are off welfare, until the first or fifteenth, until your song comes on, until you've had a drink, until you've sobered up, until you die, until you are born again to decide that there is no better time than right now to be happy . . Happiness is a journey, not a destination.

"Work like you don't need money,

Love like you've never been hurt,

And dance like no one's watching."

-Anonymous Woman

(continued on $\mathrm{pg} \mathrm{x}$ ) 
clench their fists. This does not look like "relaxation." Women need to know that birth is physical, hard work and that "finding your rhythym" helps, but aiming for complete relaxation doesn't make any sense.

- Every childbirth educator I know is convinced that her confidence, enthusiasm, and encouragement are important ways to help the women in her classes become confident in their own abilities. I agree. Don't hold back. Be wildly encouraging.

- The less lecture, the better. If we are aiming to change women's beliefs about birth and help women develop the confidence and skill they will need to tap into their inner wisdom during birth, we need to make women as active in class as they are at birth!

Let us know how YOU are changing your classes to reflect the philosophy of birth. We are eager to hear from you.

\section{Resources}

\section{Books}

Enkin, M., Kierse, M., et al. (1995). A guide to effective care in pregnancy and childbirth. New York: Oxford University Press.

\section{Letter from the Editor-continued}

I forward this on to you in part because it may have personal meaning for you at whatever your stage in life but mostly because you are concerned with perinatal education. It seems to me that "waiting for happiness" is prevalent in our society. At major life transitions, we may be especially vulnerable to experiencing disappointment that "true happiness" was only fleeting or did not arrive as anticipated.

The expectant parents with whom you work are at a major life transition point that most anticipate will result in happiness. However, their labor may or may not go as anticipated. Their infant may or may not be precisely
Goer, H.(1995). Obstetric myths versus research realities. Westport, Ct.: Bergin and Garvey.

Jordan, B. (1993). Birth in four cultures. Prospect Heights, IL: Waveland Press.

Kitzinger, S. (1991). Homebirth: The essential guide to giving birth outside the hospital. New York: Dorling Kindersley, Inc.

Klaus, M., Kennell, J. \& Klaus, P. (1993) Mothering the mother: How a doula can help you have a shorter, easier, and healthier birth. Reading, MA: Addison-Wesley Press.

Rooks, J. (1997). Midwifery and childbirth in America. Philadelphia: Temple University Press.

Wagner, M. (1994). Pursuing the birth machine: The search for appropriate birth technology. Campersdown, Australia: ACE Graphics.

Wertz R. \& Wertz, D.(1989). Lying-In: A history of childbirth in America. New Haven: Yale University Press.

\section{Videos}

Birth in the Squatting Position, available from Polymorph Films or Birth and Life Bookstore.

Gentle Birth Choices, available from Lamaze Media Center.

Suzanne Arms' Giving Birth: Challenges and Choices, available from Birthing the Future (970-884-4090).

Timeless Way: A History of Birth from Ancient to Modern Times, available from InJoy Videos.

\section{Slide Shows}

Epic Women available from Harriet Hartigan (313-677-0519). Sisters available from Patty Ramos (206-272-6965).

what they expected. And even if everything goes as well as their fondest dreams, the resulting happiness can quickly be dampened with new challenges such as sleep deprivation and/or sore nipples.

Therefore, preparing expectant parents for childbirth and parenting might include discussing the above thoughts. Are you aiding your class members to give up on the mythical path to happiness and accept the wisdom of "happiness as the way"?

-Sharron S. Humenick, RN, Ph.D., LCCE, FACCE, FAAN 